Article

\title{
The Study of A New Symmetrical Rod Phase in Mg-Zn-Gd Alloys
}

\author{
Jianhang Yue, Yun Feng, Hao Wu ${ }^{\mathbb{D}}$, Guorong Zhou, Min Zuo, Jinfeng Leng and Xinying Teng * \\ School of Materials Science and Engineering, University of Jinan, No. 336, West Road of Nanxinzhuang, \\ Jinan 250022, China \\ * Correspondence: mse_tengxy@ujn.edu.cn; Tel.: +86-137-9315-7586
}

Received: 8 July 2019; Accepted: 1 August 2019; Published: 2 August 2019

\begin{abstract}
Quasicrystal alloys have a wide application prospect because of excellent performances and characteristics; meanwhile, magnesium alloys are known as green engineering materials because of their high specific strength and light weight. Therefore, the study of Mg-Zn-Gd quasicrystal alloys is of great significance for the development of new materials. In this paper, $M g(70-x) Z_{30} G_{x}(x=3,4,5)$ alloys were prepared by a conventional casting method and the morphologies and properties of these alloys were studied. There was a new symmetrical rod phase found in the $\mathrm{Mg}_{66} \mathrm{Zn}_{30} \mathrm{Gd}_{4}$ alloy and the symmetrical rod phase was identified as a ternary phase by mapping scanning and energy dispersive spectroscopy (EDS) analysis. The $\mathrm{Zn} / \mathrm{Gd}$ ratio of the symmetrical rod phase was found to be 4.8 and the TEM images obtained were different from the typical diffraction spots patterns of quasicrystalline, which means it is unlikely to be quasicrystalline. With different melt holding time, the symmetrical rod phase evolved gradually over time from a lamellar eutectic structure; differential scanning calorimetry (DSC), heat treatment, and microhardness tests showed that the melting temperature of the rod phase was $453^{\circ} \mathrm{C}$ and that its thermal stability and microhardness are better than quasicrystalline. Hence, the symmetrical rod phase is a new kind of complex metallic alloy phase whose composition and properties are close to those of quasicrystals but is not quasicrystalline.
\end{abstract}

Keywords: Mg-Zn-Gd alloys; symmetrical rod phase; quasicrystal; morphologies and properties

\section{Introduction}

As the lightest green engineering structural material, magnesium alloy has many advantages, including high specific strength and stiffness, good shock and noise reduction performance, electromagnetic shielding, and easy processing and forming, etc. It has broad application prospects in transportation, aerospace, and military industries [1]. Shechtman et al. [2] first found the quasicrystalline phase in an Al-Mn quench alloy system in 1984. Unlike traditional crystals, quasicrystals have special symmetry of five or more times [3-6]. This structural particularity also makes them have high hardness and strength, as well as low friction coefficients, strong thermal stability, and corrosion resistance [7-9]. Therefore, introducing quasicrystals as a dispersion strengthening phase into magnesium alloys can theoretically compensate for the shortcomings of traditional magnesium alloys [10].

Quasicrystalline alloys have received more and more attention and recognition in recent decades [11,12]. In addition, studying the factors that affect the formation of quasicrystals for the synthesis and application of quasicrystals is significant. There are many factors affecting the formation of quasicrystals according to former studies, including cooling rate, composition, electronic structure, and melt treatment [13].

The quasicrystalline alloys of $\mathrm{Mg}-\mathrm{Zn}-\mathrm{Re}$ (where $\mathrm{Re}=$ rear earth element) have been extensively researched. It has been confirmed that the $\mathrm{Zn} / \mathrm{Y}$ ratios of I-phase $\left(\mathrm{Mg}_{3} \mathrm{Zn}_{6} \mathrm{Y}_{1}\right)$ and $\mathrm{W}$-phase $\left(\mathrm{Mg}_{3} \mathrm{Zn}_{3} \mathrm{Y}_{2}\right)$ are 6 and 1.5, respectively [14]. These ratios are in accordance with those for Mg-Zn-Gd alloys. In 
addition, $\mathrm{W}^{\prime}$-phase, H-phase, and other phases, which have different structures, exist in quasicrystalline alloys. Therefore, making a profound study of the structures and relationships between different phases will aid in obtaining a good understanding of the interlink among phases, which is of great significance to the study of the atomic structure of strengthened phases in high-performance magnesium alloys.

For Mg-Zn-Gd alloys, the icosahedral quasicrystal phase (I-phase) has been confirmed as being able to be made as an equilibrium phase during solidification or crystallization in a certain range of elemental components and holding time $[15,16]$. When the components or holding time change, the composition, structure, and symmetry of phases may change. In this paper, we prepared different $\mathrm{Mg}_{(70-\mathrm{x})} \mathrm{Zn}_{30}-\mathrm{Gd}_{\mathrm{x}(\mathrm{x}=3,4,5)}$ (at. \%) alloys and investigated the composition, structure, and symmetry of phases. This work focuses on the metastable phases in the Mg-Zn-Gd system; the formation mechanism of the symmetrical rod phase is also discussed.

\section{Materials and Methods}

The experimental ternary alloys with nominal component $\mathrm{Mg}_{(70-\mathrm{x})} \mathrm{Zn}_{30} \mathrm{Gd}_{\mathrm{x}(\mathrm{x}=3,4,5)}$ (at. \%) were prepared by melting high-purity $\mathrm{Mg}(99.98 \mathrm{wt} \%), \mathrm{Zn}(99.96 \mathrm{wt} \%)$, and master alloy $\mathrm{Mg}-\mathrm{Gd}(30.21 \mathrm{wt} \%)$ in an electric resistance furnace. Firstly, $\mathrm{Mg}$ and $\mathrm{Mg}-30.21 \mathrm{wt} \% \mathrm{Gd}$ alloys were placed into a graphite-clay crucible. When the temperature reached $720^{\circ} \mathrm{C}$ and the alloys previously added had melted, $\mathrm{Zn}$ was added into the molten metal. After all the alloys had become molten, the melt was kept at $720^{\circ} \mathrm{C}$ for minutes. The melt was then poured into a $200^{\circ} \mathrm{C}$ preheated steel mold and cooled slowly in the atmosphere. Protective gas composed of $\mathrm{CO}_{2}$ and $\mathrm{SF}_{6}$ was always in the process of smelting to prevent evaporation and oxidation of components during smelting.

$\mathrm{X}$-ray diffraction (Bruker D8 Advance) employing $\mathrm{Cu} \mathrm{K} \alpha$ radiation was used to determine the constitution of phases with a scanning rate of $\sim 5^{\circ} \mathrm{min}^{-1}$. The microstructure and morphology were characterized by SEM (FEI-QUANTA FEG250) equipped with EDS (X-MAX50) for analyzing the local chemical compositions of different phases and TEM (JEM-2100). The thermal stability and microhardness of phases was researched by DSC (HCT-1) and a Rockwell hardness tester. Sample preparations for TEM observations were made up of mechanical polishing and ion-beam thinning (GATAN-691).

\section{Results}

\subsection{Microstructure and Composition}

SEM images of Mg-Zn-Gd alloys with different content of $\mathrm{Gd}$ after holding for $40 \mathrm{~min}$ are displayed in Figure 1. The content of Gd in the Mg-Zn-Gd alloys seen in Figure $1 \mathrm{a}-\mathrm{c}$ is 3 at. \%, 4 at. \%, and 5 at. \%, respectively. It can be clearly seen that the phase morphologies of the alloys changed significantly. When the content of $\mathrm{Gd}$ is 3 at. \% in the $\mathrm{Mg}(70-\mathrm{x}) \mathrm{Zn}_{30}-\mathrm{Gd}_{\mathrm{x}}$ alloy (Figure 1a), three main phases are included in the alloy: a light grey pentapetaloid phase, a black punctate phase, and a dark grey matrix phase. According to the XRD patterns shown in Figure 2, these phases may be judged to be I-phase, $\alpha-\mathrm{Mg}$ phase, $\mathrm{Mg}_{7} \mathrm{Zn}_{3}$ phase, respectively. This is consistent with the report in the literature by Gröbner et al. [17]. The TEM images of the light grey pentapetaloid phase (shown in Figure 5a,b) also appear to be a typical quasicrystal diffraction spot, which can also prove that the light grey pentapetaloid phase is an icosahedral quasicrystal (I-phase). 


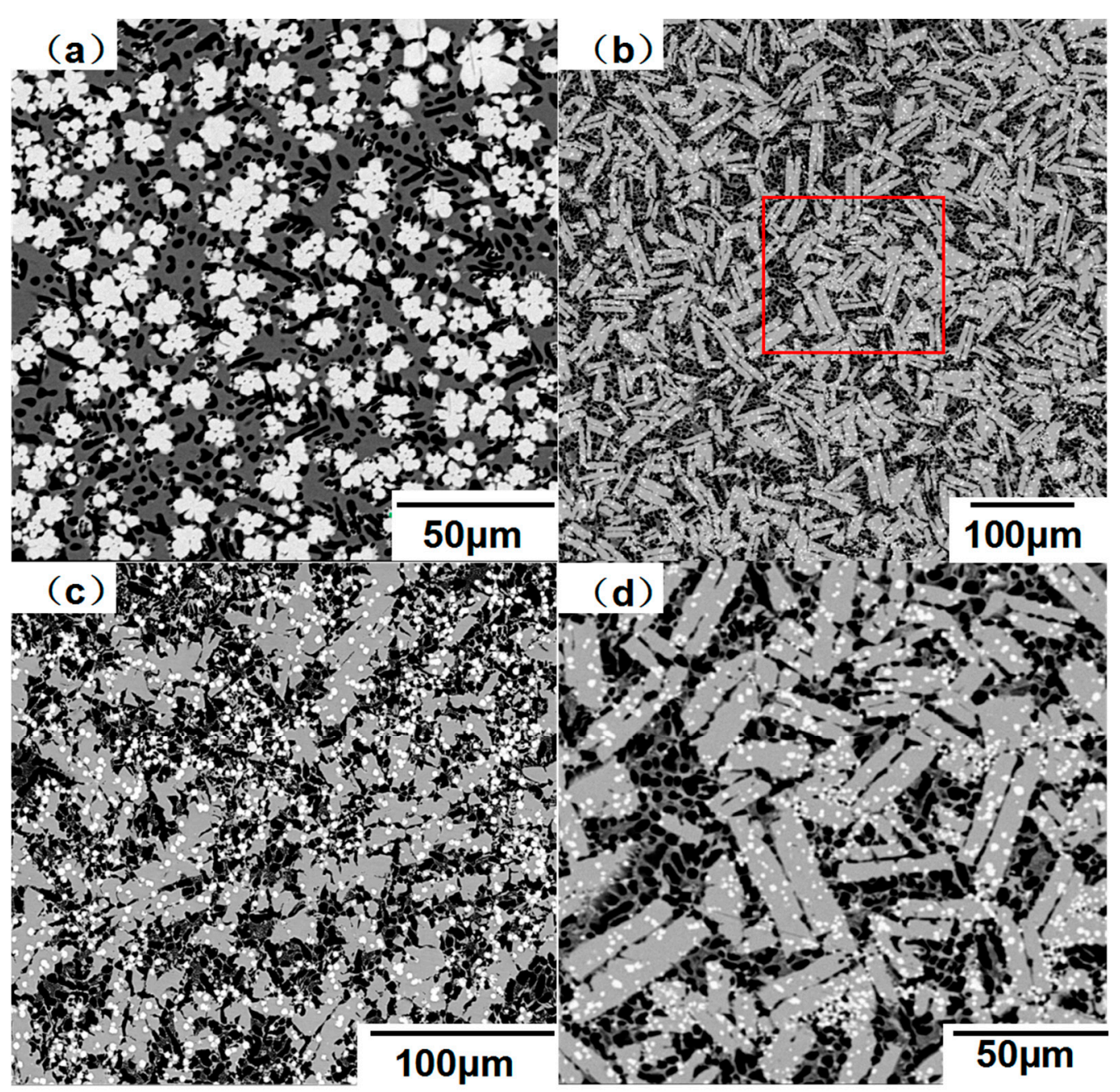

Figure 1. Mg-Zn-Gd alloys with different Gd content after holding for 40 min: (a) $\mathrm{Mg}_{67} \mathrm{Zn}_{30} \mathrm{Gd}_{3}$; (b)

$\mathrm{Mg}_{66} \mathrm{Zn}_{30} \mathrm{Gd}_{4} ;(\mathbf{c}) \mathrm{Mg}_{65} \mathrm{Zn}_{30} \mathrm{Gd}_{5} ;$ (d) locally enlarged image of (b).

Figure $1 \mathrm{~b}$ is an SEM image of the $\mathrm{Mg}_{66} \mathrm{Zn}_{30} \mathrm{Gd}_{4}$ alloy and Figure $1 \mathrm{~d}$ is a local enlargement of Figure $1 \mathrm{~b}$. When the content of $\mathrm{Gd}$ reaches 4 at. \%, the major phases except the black phase $\alpha-\mathrm{Mg}$ and dark grey phase $\mathrm{Mg}_{7} \mathrm{Zn}_{3}$ are the light grey symmetrical rod phase and white punctate phase, which can be clearly seen from Figure 1d. The distribution of the symmetrical rod phase is disorderly and its length is $20 \mu \mathrm{m}$ to $50 \mu \mathrm{m}$. The white punctate phase is dispersed in the alloy with a small volume. In the $\mathrm{Mg}_{65} \mathrm{Zn}_{30} \mathrm{Gd}_{5}$ alloy (Figure 1c), the other three phases do not change a lot but the light grey phase appears irregularly shaped, which is quite different from the symmetrical rod phase.

As shown in the XRD patterns (Figure 2), when the content of Gd is 3 at. \%, the peaks of the I-phase appear in the pattern of Figure 2a. However, the I-phase peaks are not detected in patterns of alloys with 4 at. \% and 5 at. \% Gd. On the contrary, in Figure $2 b, c$, phase Gd-Zn is found and there are obvious peaks in the places where $2 \theta$ is $23,24.2,36,38$, and 40.5 , and these peaks are not the diffraction peaks of the other three phases. Thus, it can be inferred that these peaks may be the diffraction peaks of the symmetrical rod phase. Hence, deducing from Figures 1 and 2, the symmetrical rod phase is unlikely to be the icosahedral phase of quasicrystals. 


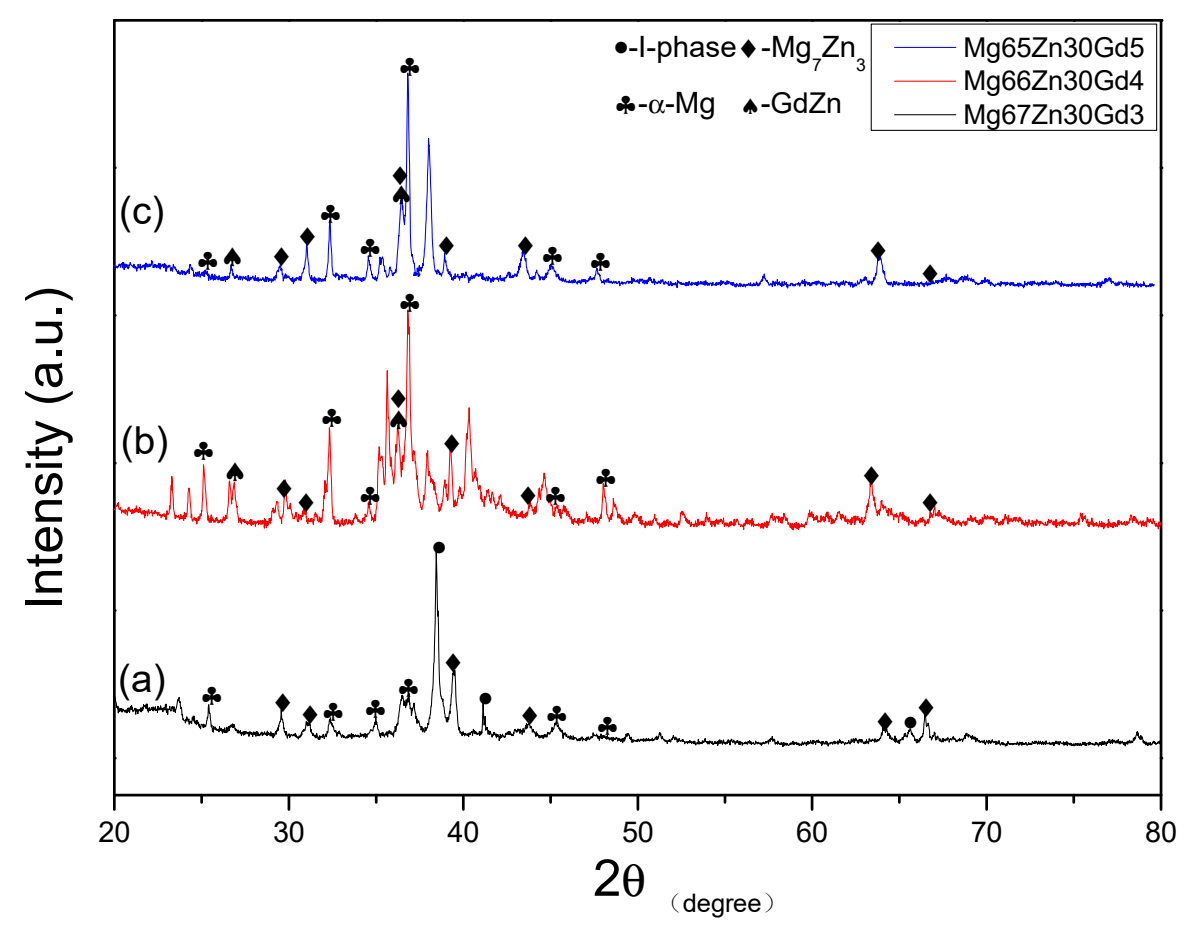

Figure 2. XRD patterns of different $\mathrm{Mg}-\mathrm{Zn}-\mathrm{Gd}$ alloys: (a) $\mathrm{Mg}_{67} \mathrm{Zn}_{30} \mathrm{Gd}_{3}$; (b) $\mathrm{Mg}_{66} \mathrm{Zn}_{30} \mathrm{Gd}_{4}$; (c) $\mathrm{Mg}_{65} \mathrm{Zn}_{30} \mathrm{Gd}_{5}$.

Figure 3 is a mapping scanning analysis of the main morphologies of the $\mathrm{Mg}_{66} \mathrm{Zn}_{30} \mathrm{Gd}_{4}$ alloy. It is obvious that the white punctate phase appears black in $\mathrm{Mg}$ and bright in the $\mathrm{Zn}$ and Gd graphs. This means that the white punctate phase contains almost no Mg element but embodies $\mathrm{Zn}$ and Gd, which is a kind of Gd-Zn alloy. By analyzing Figures 2 and 3, it can be approximately determined that the white punctate phase is the Gd-Zn phase. The white punctate phase Gd-Zn is mostly distributed over the symmetrical rod phase. Hence, the formation of this phase maybe due to the increase of Gd content, which means that the excess Gd element precipitates during the solidification of the alloy and reacts with $\mathrm{Zn}$ to form the $\mathrm{Gd}-\mathrm{Zn}$ phase. In addition, the light grey symmetrical rod phase has bright colors in all three scanning images, meaning that the phase can be ascertained as a ternary phase containing $\mathrm{Mg}, \mathrm{Zn}$, and Gd elements.

To further research the phase composition, EDS analysis of the pentapetaloid I-phase and symmetrical rod phase was carried out. As shown in Figure 4, points 1 and 2 are the constituents of the pentapetaloid I-phase and the symmetrical rod phase, respectively. The atomic composition of the pentapetaloid I-phase is 65.82 at. \% Mg, 29.22 at. \% Zn, and 4.96 at. \% Gd. Thus, it can be seen that the ratio of $\mathrm{Zn} / \mathrm{Gd}$ in the pentapetaloid I-phase is 5.89 , which is very close to the theoretical value $\mathrm{Mg}_{3} \mathrm{Zn}_{6} \mathrm{Gd}_{1}$ [18] of the quasicrystalline phase in the Mg-Zn-Re system. The existence of the quintic rotational symmetry axis in Figure $5 b$ and the EDS energy spectrum analysis further prove that the determination of the quintic petal phase as a quasicrystal phase is correct. The atomic composition of the symmetrical rod phase is 77.52 at. $\% \mathrm{Mg}, 18.59$ at. $\% \mathrm{Zn}$, and 3.89 at. \% Gd, and the ratio of $\mathrm{Zn} / \mathrm{Gd}$ is approximately 4.8. This is much less than the theoretical value of quasicrystalline.

Moreover, the TEM images of the symmetrical rod phase are shown in Figure $5 c$,d. It is obvious that the selected-area electron diffraction spots are very complex and different from the typical diffraction spots pattern (Figure 5b) of quasicrystalline; it may include various phases judging by the signed rectangles of different colors, but it does not include the quasicrystal phase. Jiang et al. [19] have reported that the ratio of $\mathrm{Zn} / \mathrm{Gd}$ in the $\mathrm{W}$-phase, which is common in $\mathrm{Mg}$ - $\mathrm{Zn}$-Re alloys and is similar to the quasicrystalline phase, is about 1.5. As per the previous analysis, the $\mathrm{Zn} / \mathrm{Gd}$ ratio of the symmetrical rod phase is 4.8, which is not only far from 1.5 ( the ratio of W-phase), but also different from 6 ( the ratio of I-phase ). Therefore, by analyzing the SEM, XRD, EDS, and TEM graphics of the symmetrical 
rod phase, the composition of this phase is similar to that of quasicrystals, but its structure does not seem to have the characteristics of typical quasicrystals.
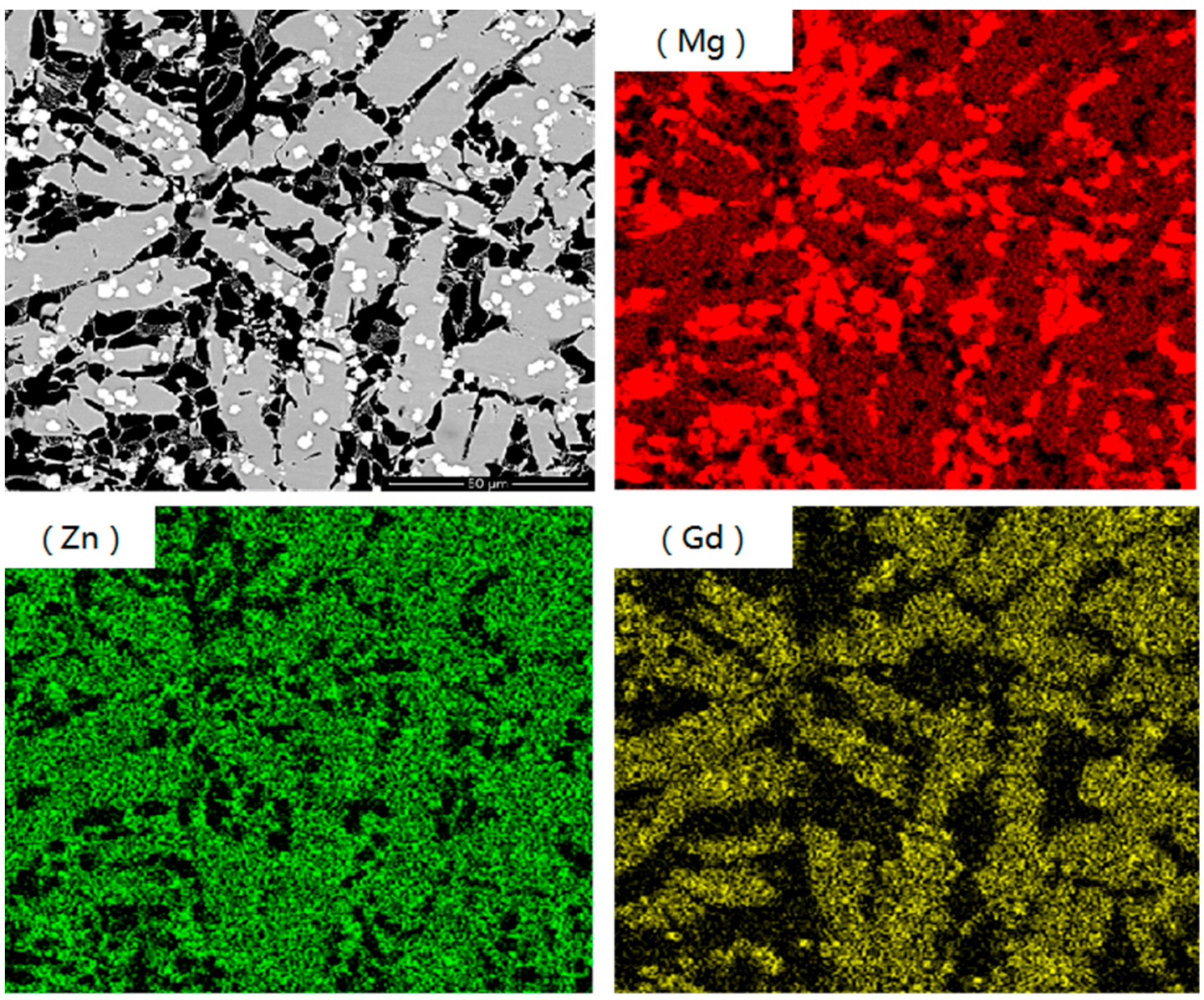

Figure 3. Mapping scanning analysis of the $\mathrm{Mg}_{66} \mathrm{Zn}_{30} \mathrm{Gd}_{4}$ alloy.

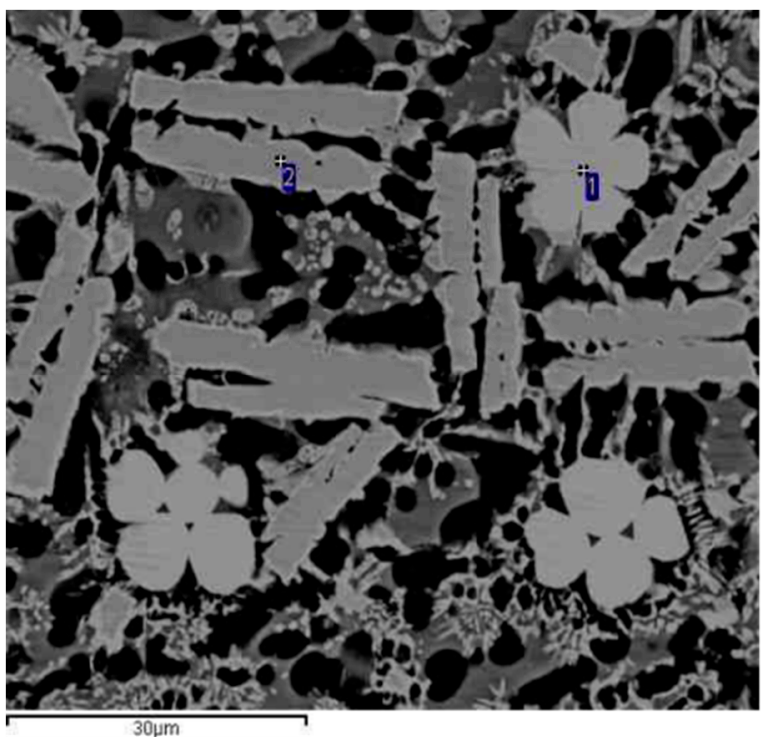

\begin{tabular}{ccc} 
& Element & At\% \\
\cline { 2 - 3 } $\mathrm{P}_{1}$ & $\mathrm{Mg}$ & 65.82 \\
& $\mathrm{Zn}$ & 29.22 \\
& $\mathrm{Gd}$ & 4.96 \\
\hline
\end{tabular}

Figure 4. EDS analysis of different phases: (1) pentapetaloid phase; (2) symmetrical rod phase. 


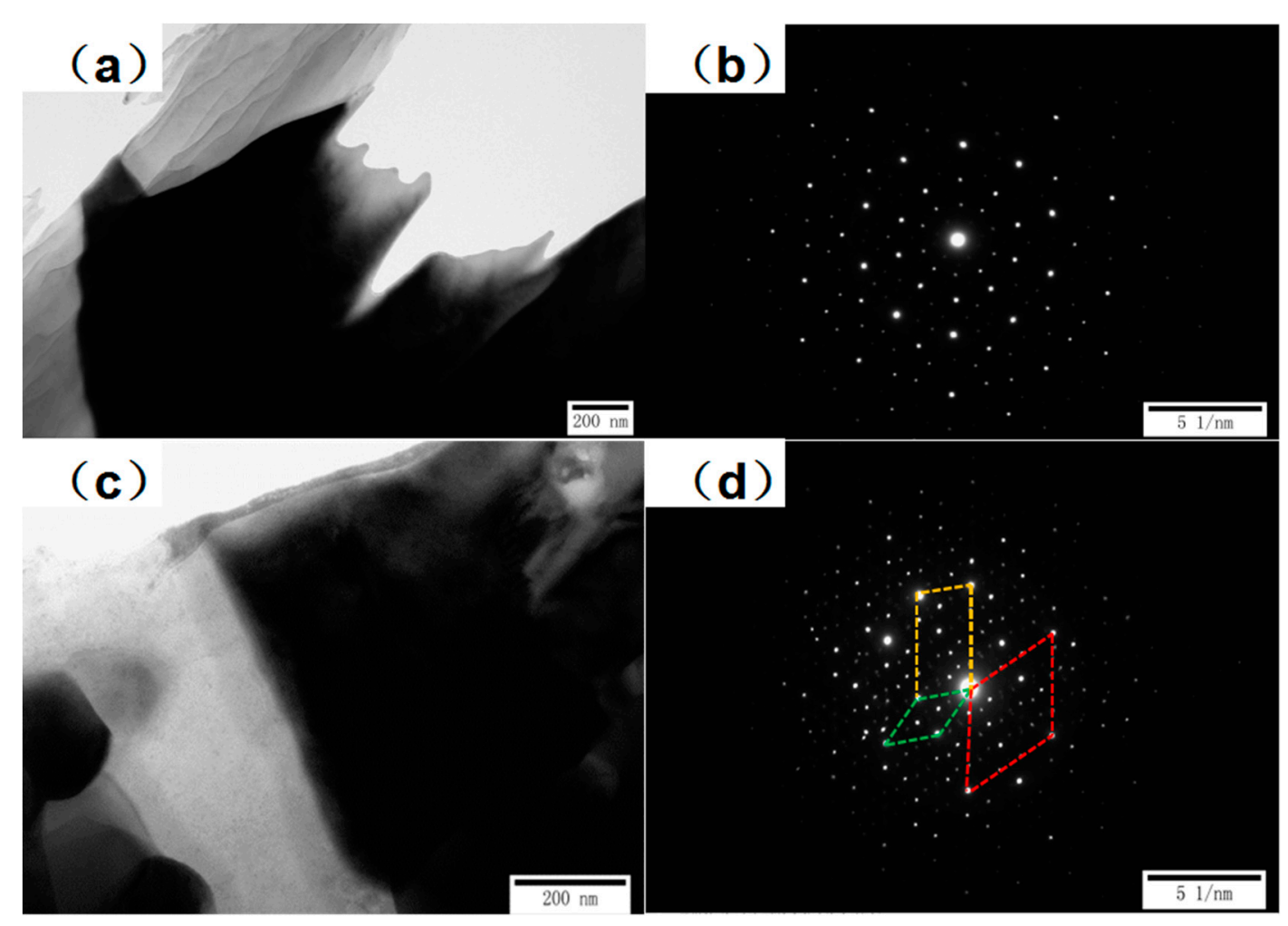

Figure 5. TEM images of different phases: $(\mathbf{a}, \mathbf{b})$ pentapetaloid phase; $(\mathbf{c}, \mathbf{d})$ symmetrical rod phase.

\subsection{Morphological Evolution}

In order to investigate the formation and stability of the symmetrical rod phase, samples of the $\mathrm{Mg}_{66} \mathrm{Zn}_{30} \mathrm{Gd}_{4}$ alloy with different holding time at $720{ }^{\circ} \mathrm{C}$ were selected for research. As shown in Figure $6 \mathrm{a}$, when the holding time is $5 \mathrm{~min}$, most of the phases in the alloy are strip-like lamellar eutectic phases with a longitudinal midline running through the structure; meanwhile, there are some black $\alpha-\mathrm{Mg}$ phases and white dotted Gd-Zn phases, which show that the GdZn phase is easy to form in the solidification of the alloy. After being held for $10 \mathrm{~min}$ (Figure 6b), the strip-like lamellar eutectic phases were less than before, and the white dotted phases did not increase significantly; however, the symmetrical rod phases had preliminarily formed. In the blue area of Figure $6 c$, the symmetrical rod phases had basically formed, and in the red area, it was half rod phase and half lamellar eutectic structure. Hence, it can be inferred that the symmetrical rod phase evolved gradually over time from the lamellar eutectic structure with the longitudinal midline as the demarcation line. When the holding time was $15 \mathrm{~min}$, the evolution of the symmetrical rod phases had finished, and there was no lamellar eutectic structure which remained (Figure 6d). In Figure 6e, the size of the symmetrical rod phase increased to $40-70 \mu \mathrm{m}$ but the morphologies essentially remained unchanged, which reflected the good stability of the symmetrical rod phase.

From Figure 7, it can be seen that the XRD diffraction patterns of the alloys after holding for 5, 10, and $15 \mathrm{~min}$ are basically the same and they all contain three identical known phases: $\mathrm{Mg}_{7} \mathrm{Zn}_{3}, \mathrm{Gd}-\mathrm{Zn}$ and $\alpha-\mathrm{Mg}$. At the same time, peaks appear at positions 23, 24.2, 36, and $40.52 \theta$, which is consistent with Figure $2 \mathrm{~b}$. Based on the analysis of Figures 6 and 7, it can be inferred that the symmetrical rod phase appeared early in the alloy, and gradually evolved from the lamellar network structure to the symmetrical rod phase structure. 


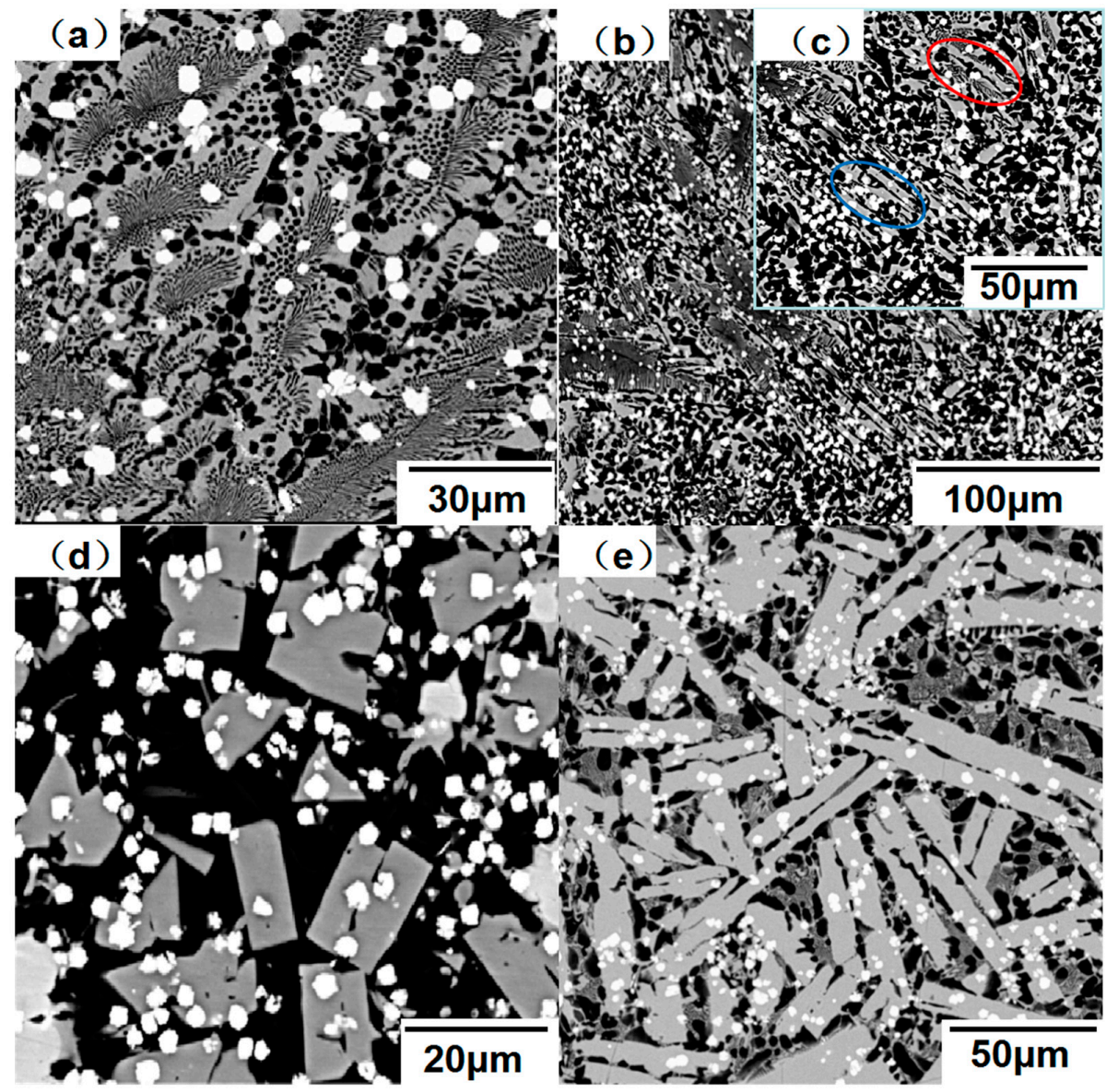

Figure 6. SEM images of the $\mathrm{Mg}_{66} \mathrm{Zn}_{30} \mathrm{Gd}_{4}$ alloy after different holding times at $720{ }^{\circ} \mathrm{C}$ : (a) $5 \mathrm{~min}$; (b) $10 \mathrm{~min}$; (c) magnification of (b); (d) $15 \mathrm{~min}$; (e) $80 \mathrm{~min}$.

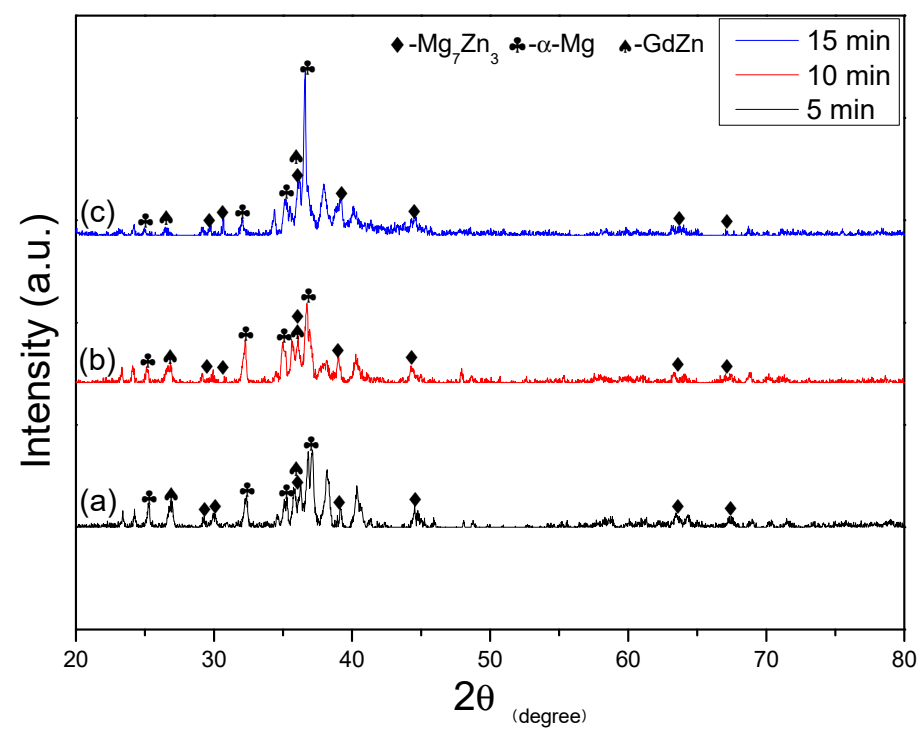

Figure 7. XRD patterns of the $\mathrm{Mg}_{66} \mathrm{Zn}_{30} \mathrm{Gd}_{4}$ alloy after different holding times at $720{ }^{\circ} \mathrm{C}$ : (a) $5 \mathrm{~min}$; (b) $10 \mathrm{~min}$; (c) $15 \mathrm{~min}$.

\subsection{Thermal Stability}

In addition, thermodynamic and microhardness tests of the petaloid quasicrystal phase (I-phase) and the symmetrical rod phase were carried out. Figure 8a shows the DSC analysis curves of the 
$\mathrm{Mg}_{67} \mathrm{Zn}_{30} \mathrm{Gd}_{3}$ and $\mathrm{Mg}_{66} \mathrm{Zn}_{30} \mathrm{Gd}_{4}$ alloys. It can be seen that when the temperature reaches $345^{\circ} \mathrm{C}$, both lines have endothermic peaks, which is due to the melting of $\mathrm{Mg}_{7} \mathrm{Zn}_{3}$. Another endothermic peak of the $\mathrm{Mg}_{67} \mathrm{Zn}_{30} \mathrm{Gd}_{3}$ alloy appears at $417^{\circ} \mathrm{C}$, and according to the reports of Zhang et al. [16], this is the melting peak of the petal-like quasicrystal phase; meanwhile, the melting peak of the symmetrical rod phase in the $\mathrm{Mg}_{66} \mathrm{Zn}_{30} \mathrm{Gd}_{4}$ alloy appears at $453^{\circ} \mathrm{C}$, which means that the symmetrical rod phase may have a better thermal stability than the petal-like quasicrystalline phase. In order to verify the above hypothesis, samples of the $\mathrm{Mg}_{67} \mathrm{Zn}_{30} \mathrm{Gd}_{3}$ and $\mathrm{Mg}_{66} \mathrm{Zn}_{30} \mathrm{Gd}_{4}$ alloys were heat-treated at $430{ }^{\circ} \mathrm{C}$ for study. The results shown in Figure $8 b, c$ indicate that the morphology of the quasicrystalline phase changed dramatically as a result of melting and that the petal-like morphology became a lamellar network structure; however, the morphology of the symmetrical rod phase remained stable in the main and only a few lamellar eutectic structures occurred in the interior. The microhardness of the quasicrystalline and symmetrical rod phases before and after heat treatment were studied; the results show that the microhardness of the symmetrical rod phase did not decrease obviously but that that of the quasicrystalline phase decreased a lot. All the above analyses prove that the symmetrical rod phase has a better thermal stability than the petal-like quasicrystalline phase.
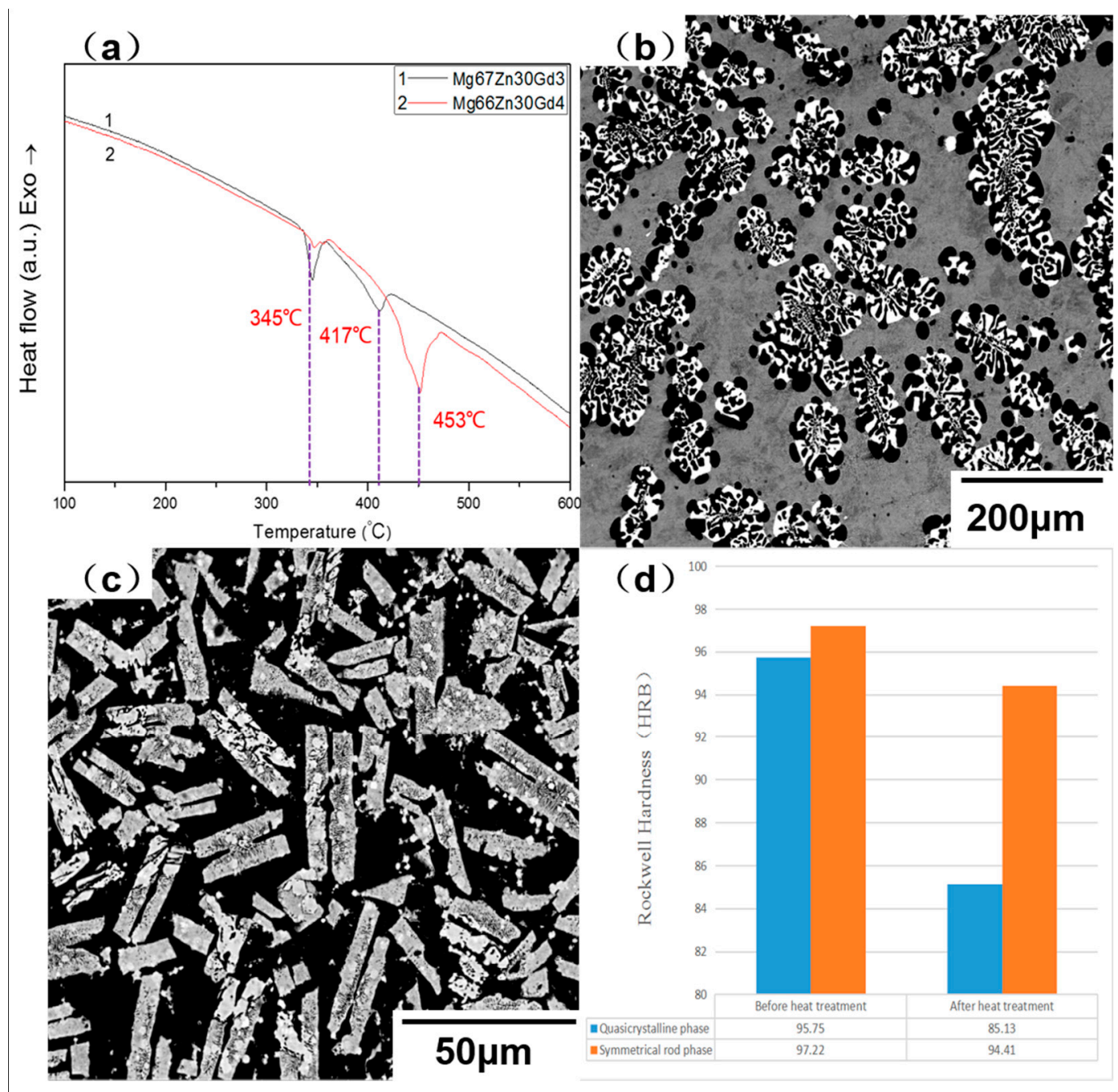

Figure 8. (a) Differential scanning calorimetry (DSC) analysis curves of the different Mg-Zn-Gd alloys: $1-\mathrm{Mg}_{67} \mathrm{Zn}_{30} \mathrm{Gd}_{3}, 2-\mathrm{Mg}_{66} \mathrm{Zn}_{30} \mathrm{Gd}_{4}$; (b,c) SEM images of $\mathrm{Mg}_{67} \mathrm{Zn}_{30} \mathrm{Gd}_{3}$ and $\mathrm{Mg}_{66} \mathrm{Zn}_{30} \mathrm{Gd}_{4}$ after heat treatment at $430{ }^{\circ} \mathrm{C}$, respectively; (d) microhardness of the quasicrystalline and symmetrical rod phases before and after heat treatment. 


\section{Discussion}

In this study, the symmetrical rod phase was found in the $\mathrm{Mg}_{66} \mathrm{Zn}_{30} \mathrm{Gg}_{4}$ alloy but not in the other two alloys considered, which indicates that the formation of the phase is related to the content of $\mathrm{Gd}$, i.e., the ratio of $\mathrm{Zn}$ to $\mathrm{Gd}$. The diffraction pattern of the symmetrical rod phase was found to be very complex, probably because it evolved from a lamellar eutectic structure, and its $\mathrm{Zn} / \mathrm{Gd}$ ratio was observed to be close to the quasicrystal ratio, thus forming a more complex internal structure. Moreover, the increase of thermal stability and microhardness of the phase may also be due to the complex structure of the phase. Because the composition, $\mathrm{Zn} / \mathrm{Gd}$ ratio, phase transition temperature, and microhardness of the symmetrical rod phase are similar to those of a quasicrystal phase, but its electron diffraction spot does not show the characteristics of a typical quasicrystal phase, we consider it to be a new kind of complex metallic alloy phase whose composition and properties are close to those of quasicrystals but is not quasicrystalline. The specific spatial structure and related parameters of the phase need to be further studied in the future.

\section{Conclusions}

In this work, the $\mathrm{Mg}_{(70-\mathrm{x})} \mathrm{Zn}_{30} \mathrm{Gd}_{\mathrm{x}(\mathrm{x}=3,4,5)}$ alloys with different content of $\mathrm{Gd}$ were prepared and the morphologies and properties of these alloys were studied: (1) the main phases were found to be a pentapetaloid phase for the $\mathrm{Mg}_{67} \mathrm{Zn}_{30} \mathrm{Gd}_{3}$, a symmetrical rod phase for the $\mathrm{Mg}_{66} \mathrm{Zn}_{30} \mathrm{Gd}_{4}$ alloy, and an irregularly shaped phase for the $\mathrm{Mg}_{65} \mathrm{Zn}_{30} \mathrm{Gd}_{5}$ alloy; (2) the symmetrical rod phase was found to consists of three elements $(\mathrm{Mg}, \mathrm{Zn}$, and $\mathrm{Gd}$ ), its $\mathrm{Zn} / \mathrm{Gd}$ ratio was obtained as 4.8 (which is close to but not in conformity with the requirements of quasicrystals) and its electron diffraction spots were complex and had no obvious quasicrystal phase characteristics; (3) this phase was found to evolve gradually over time from the lamellar eutectic structure and to be able to exist in alloy melt for a long time. The melting temperature of the symmetrical rod phase was $453{ }^{\circ} \mathrm{C}$, and its thermal stability and microhardness were found to be better than those of quasicrystal phase; (4) the composition and phase transition temperature of the symmetrical rod phase were found to be close to those of a quasicrystal phase, but its electron diffraction pattern was seen to have no characteristics of a quasicrystal phase, so it may be a new kind of complex metal alloy phase, and needs further study.

Author Contributions: Conceptualization, J.Y.; data curation, Y.F.; formal analysis, J.Y.; methodology, Y.F.; software, H.W.; validation, G.Z., M.Z., and J.L.; writing—original draft, J.Y.; writing—review and editing, X.T.

Funding: This research was funded by the National Natural Science Foundation of China (grant nos. 51571102, 51701081, and 51871111), the Young-Aged Talents Lifting Project of the Shandong Association for Science and Technology (grant no. 301-1505001, recorded by the University of Jinan), and the Shandong Provincial Natural Science Foundation (grant no. ZR2017BEM001).

Acknowledgments: Thank you to my instructor, the teachers and students of the project group for their help, and also to the fundings.

Conflicts of Interest: The authors declare no conflict of interest.

\section{References}

1. Yuan, G.; Amiya, K.; Kato, H.; Inoue, A. Structure and mechanical properties of cast quasicrystal-reinforced Mg-Zn-Al-Y base alloys. J. Mater. Res. 2004, 19, 1531-1538. [CrossRef]

2. Shechtman, D.; Blech, I.; Gratias, D.; Cahn, J.W. Metallic phase with long-range orientational order and no translational symmetry. Phys. Rev. Lett. 1984, 53, 1951. [CrossRef]

3. Levine, D.; Steinhardt, P.J. Quasicrystals: A new class of ordered structures. Phys. Rev. Lett. 1984, 53, 2477. [CrossRef]

4. Fischer, S.; Exner, A.; Zielske, K.; Perlich, J.; Deloudi, S.; Steurer, W.; Lindner, P.; Förster, S. Colloidal quasicrystals with 12-fold and 18-fold diffraction symmetry. Proc. Natl. Acad. Sci. USA 2011, 108, 1810-1814. [CrossRef] [PubMed] 
5. Gierer, M.; Hove, M.A.; Goldman, A.I.; Shen, Z.; Chang, S.L.; Jenks, C.J.; Zhang, C.M.; Thiel, P.A. Structural Analysis of the Fivefold Symmetric Surface of the A 170 P d 21 M n 9 Quasicrystal by Low Energy Electron Diffraction. Phys. Rev. Lett. 1997, 78, 467. [CrossRef]

6. Zoorob, M.E.; Charlton, M.D.B.; Parker, G.J.; Baumberg, J.J.; Netti, M.C. Complete photonic bandgaps in 12-fold symmetric quasicrystals. Nature 2000, 404, 740-743. [CrossRef] [PubMed]

7. Gröbner, J.; Kozlov, A.; Fang, X.Y.; Geng, J.; Nie, J.F.; Schmid-Fetzer, R. Phase equilibria and transformations in ternary Mg-rich Mg-Y-Zn alloys. Acta Mater. 2012, 60, 5948-5962. [CrossRef]

8. Baake, M. Quasicrystals: An Introduction to Structure, Physical Properties and Applications; Suck, J.B., Schreiber, M., Häussler, P., Eds.; Springer: Berlin, Germany, 2002.

9. Vogel, M.; Kraft, O.; Dehm, G.; Arzt, E. Quasi-crystalline grain-boundary phase in the magnesium die-cast alloy ZA85. Scr. Mater. 2001, 45, 517-524. [CrossRef]

10. Zhang, J.; Jia, P.; Zhao, D.; Zhou, G.; Teng, X. Melt holding time as an important factor on the formation of quasicrystal phase in Mg67Zn30Gd3 alloy. Phys. B Condens. Matter 2018, 533, 28-32. [CrossRef]

11. Tanaka, R.; Ohhashia, S.; Fujitaae, N.; Demurabc, M.; Yamamotob, A.; Katod, A.; Tsai, A.P. Application of electron backscatter diffraction (EBSD) to quasicrystal-containing microstructures in the Mg-Cd-Yb system. Acta Mater. 2016, 119, 193-202. [CrossRef]

12. Jeon, S.Y.; Kwon, H.; Hur, K. Intrinsic photonic wave localization in a three-dimensional icosahedral quasicrystal. Nat. Phys. 2017, 13, 363. [CrossRef]

13. Huang, H.; Tian, Y.; Yuan, G.; Chen, C.; Ding, W.; Wang, Z. Formation mechanism of quasicrystals at the nanoscale during hot compression of Mg alloys. Scr. Mater. 2014, 78, 61-64. [CrossRef]

14. Huang, H.; Tian, Y.; Yuan, G.; Chen, C.; Ding, W.; Wang, Z. Precipitation of secondary phase in Mg-Zn-Gd alloy after room-temperature deformation and annealing. J. Mater. Res. Technol. 2018, 7, 135-141. [CrossRef]

15. Tian, Y.; Huang, H.; Yuan, G.; Chen, C. Nanoscale icosahedral quasicrystal phase precipitation mechanism during annealing for Mg-Zn-Gd-based alloys. Mater. Lett. 2014, 130, 236-239. [CrossRef]

16. Zhang, J.; Teng, X.; Xu, S.; Ge, X.; Leng, J. Temperature dependence of resistivity and crystallization behaviors of amorphous melt-spun ribbon of Mg66Zn30Gd4 alloy. Mater. Lett. 2017, 189, 17-20. [CrossRef]

17. Gröbner, J.; Kozlova, A.; Fang, X.Y.; Zhu, S.; Nie, J.F. Phase equilibria and transformations in ternary Mg-Gd-Zn alloys. Acta Mater. 2015, 90, 400-416. [CrossRef]

18. Sugiyama, K.; Yasuda, K.; Ohsuna, T.; Hiraga, K. The structures of hexagonal phases in Mg-Zn- $\operatorname{Re}(\operatorname{Re}=\mathrm{Sm}$ and Gd) alloys. Z. Fur Krist. 1998, 213, 537-543. [CrossRef]

19. Jiang, H.; Qiao, X.; Xu, C.; Kamado, S.; Wu, K.; Zheng, M. Influence of size and distribution of W-phase on strength and ductility of high strength Mg-5.1 Zn-3.2 Y-0.4 Zr-0.4 Ca alloy processed by indirect extrusion. J. Mater. Sci. Technol. 2018, 34, 277-283. [CrossRef] 